\title{
빅딜, 오픈액세스, 구글학술검색과 대학도서관의 전자학술정보구독 \\ Big Deal, Open Access, Google Scholar and the Subscription of Electronic Scholarly Contents at University Libraries
}

\author{
심원식 (Wonsik Shim)*
}

\begin{abstract}
초 록
현재 국내외 대학도서관의 전자학술정보 입수는 일명 빅딜로 불리는 수백, 수천 종의 전자학술지 묶음을 다년간, 고정된 인상율로 계약하는 구독방식이 주류를 이루고 있다. 1990년대 중반에 시작된 이러한 구독방식은 대학도서관과 이용자에게 많은 장점을 제공했다. 하지만 이들 패키지의 가격이 지속적으로 상승함에 따라 이러한 방식의 지속가능성에 대한 의문이 제기되고 있다. 현재까지 pay-per-view 방식을 제외하면 구독기반 모형의 구체적인 대안은 제시되지 않고 있으며 향후 도서관 예산문제가 심각한 뇌관으로 남아있다. 2000 년대 초반 시작된 오픈액세스 운동은 다양한 방법으로 학술지의 출판과 유통의 장벽을 제거하고 있다. 오픈액세스 출판 규모는 매년 두 자릿수로 증가하고 있고, 오픈액세스 학술지 논문은 Scopus와 Web of Science 인용데이터베이스에의 편입비율이 $20 \%$ 에 육박하는 등 양적, 질적인 성장을 보이고 있다. 2004년에 시작된 구글 학술검색은 현재 대다수 학술출판사의 학술지 논문에 대한 편리한 검색 및 접근 도구로 성장하고 있다. 비록 학술지 선택의 기준, 제한된 검색 기능, 독점화에 대한 우려 등이 있지만 구글 학술검색을 대학도서관 데이터베이스의 대안으로 진지하게 주목할 필요가 있다. 대학도서관의 예산 문제, 오픈액세 스 출판의 활성화, 구글 학술검색과 같은 무료 도구의 성장은 구독기반 모형을 대체할 수 있는 파괴적인 변화로 인식되고 있으며 대학도서관 사서는 새로운 환경에 대한 구체적인 대응을 고민해야 한다.
\end{abstract}

\section{ABSTRACT}

The dominant model of acquiring scholarly contents at academic libraries is so called big deal where libraries subscribe to a bundle of hundreds, if not thousands of journals in a multi-year contract with fixed annual rate increase. The bid deal, started in the mid-1990s, offered a number of advantages for academic libraries and their users. However, escalating prices for these packages have become a serious issue casting doubts about the sustainability of the subscription-based model. At the moment, it appears there is no viable alternative other than pay-per-view method that is being tested at some libraries. Libraries' budget situation will remain a key factor that might change the situation. Open access started in the 2000s as a vehicle to eliminate barriers to publishing and distributing peer-reviewed scholarly journal articles. Open access publishing is witnessing two-digit growth annually. Open access articles now occupy close to 20\% of two major citation databases: Scopus and Web of Science. Google Scholar service, debuted in late 2004, is now a popular tool for discovering and accessing scholarly articles from a vast selection of journals around the world. There is a call for taking Google Scholar seriously as a potential replacement of library databases amid concerns regarding the quality of journals indexed, limited search capabilities vis-à-vis library databases, and monopoly of public goods. Escalating budget problems, rapid growth of open access publishing and the emergence of powerful free tool, such as Google Scholar, need to be taken seriously as these forces might bring disruptive changes to the existing subscription-based model of scholarly contents at academic libraries

키워드: 전자정보, 전자학술정보, 빅딜, 오픈액세스, 구글 학술검색, 대학도서관, 파괴적 변화 electronic information, electronic scholarly information, big deal, open access, Google Scholar, academic libraries, disruptive change, journal subscription, electronic journals

* 성균관대학교 문헌정보학과 교수(wonsikshim@skku.edu)

- 논문접수일자 : 2012년 11월 19일 - 최초심사일자 : 2012년 11월 23일 - 게재확정일자 : 2012년 12월 14일

- 정보관리학회지, 29(4), 143-163, 2012. 〔http://dx.doi.org/10.3743/KOSIM.2012.29.4.143〕 


\section{1. 서 론}

만약 10 년 후에 전세계에서 발행되는 대부 분의 학술 자료가 인터넷을 통해 무료로 발간 되고, 이용자들이 제한 없이 접근할 수 있게 된다면 어떻게 될까? 이러한 변화는 특히 대 학도서관과 사서의 업무에 어떤 변화를 가져 오고, 대학도서관과 이용자와의 관계는 어떻게 될까?

대학도서관은 오랜 기간 동안 교수, 연구자 와 학생을 대신해 다양한 학술서적, 학술지 및 자료를 선별하여 구입하여 제공해왔다. 인터넷 이 보급되고 인쇄형태의 자료가 온라인 전자형 태로 바뀌었어도, 자료획득의 방식이 구입을 통 한 소장에서 구독을 통한 접근으로 변화된 것 을 제외하면, 대학도서관의 이러한 기능은 기 본적으로 유지되어 왔다. 최근의 추세는 대규모 의 학술지나 학술자료를 소수의 대형출판사 혹 은 데이터베이스업체를 통해, 여러 도서관이 컨 소시엄을 구성해서 다년계약으로 구독하는 형 태의 자료획득 방식이 대학도서관의 해외학 술정보를 입수하는 주된 방편으로 자리잡았다. 국내 대다수의 대학도서관은 한국과학기술정 보연구원(KISTI) 에서 주관하는 KESLI(Korea Electronic Site License Initiative) 컨소시엄 과 한국교육학술정보원(KERIS)의 해외전자 정보 컨소시엄을 통해 해외전자학술정보를 구 독하고 있다. 컨소시엄을 통한 전자학술정보 의 구독은 1990년대 중반에 시작되어 매우 빠 른 속도로 대학도서관계로 확산되었다. 하지 만 이제는 당연하게 여겨지는 이러한 전자학
술정보의 구독 방식도 언젠가는 변하게 될 것 이다.

본 논문은 향후 국내 대학도서관의 전자학술 정보의 입수 및 제공에 영향을 미치는 파괴적인 변화에 대해 살펴보고자 한다. 특히 빅딜이라고 불리는 묶음 형태의 수백 혹은 수천 종의 전자 학술지를 출판사로부터 다년계약을 통한 구독 형태로 입수하는 현재의 상황에 대한 분석을 제 시하고자 한다. 이러한 분석을 통해 현재의 빅 딜 형태의 구독 모형이 향후 어떻게 변화할 수 있는지 가늠하고, 어떤 혁신이 잠재적으로 파괴 적 변화(disruptive change, Christensen, 1997; Danneels, 2004)로 대두하고 있는지 살피고자 한다.

본 연구에서 주목하는 첫 번째 잠재적인 파 괴적 변화는 유료액세스(Toll Access, TA)에 대한 대안으로 최근 10 년 동안 학술커뮤니케이 션의 장에서 시도되고 있는 오픈액세스(Open Access, $\mathrm{OA}$ )이다. 오픈액세스에 대해서는 그 것의 필요성, 관련된 다양한 시도들, 그리고 영 향력에 대한 여러 연구가 진행된 바 있다. 오픈 액세스에 대한 방대한 관련 자료 및 연구의 종 합적인 서지는 Charles Bailey Jr.에 의해 2005 년부터 체계적으로 수집되어 웹을 통해 접근할 수 있다.1) 본 연구에서는 오픈액세스로 출판되 는 논문의 전체적인 규모가 어느 정도 수준이 며 기존의 유료액세스 환경을 획기적으로 바꿀 수 있을 것인지를 살펴보고자 한다. 본 논문에 서 주목하는 두 번째 잠재적인 파괴적 변화는 구글 학술검색(Google Scholar)이다. 2004년 말에 구글에 의해 시작된 구글 학술검색은 그

1) Open Access Bibliography: Liberating scholarly literature with e-prints and open access journals. http://digital-scholarship.org/oab/oab.htm 
간 꾸준히 그 기능과 편입된 학술정보의 양을 늘려옴으로써 잠재적으로 대학도서관이 이용 하고 있는 학술데이터베이스를 대체할 수 있는 서비스로 인식되고 있다(Chen, 2010a/2010b; Howland et al., 2009; Pomerantz, 2006). 만 약 향후 전자학술지의 출판이 주로 오픈액세스 를 통해 제공된다면 이미 이용자에게 편리하고 익숙한 검색 인터페이스를 학술정보 검색에 적 용한 구글 학술검색의 영향력이 매우 클 것으 로 전망된다. 그런 관점에서 현재 구글 학술검 색의 기능과 성능을 살펴보는 것은 매우 중요 하다.

본 논문에서 논의하고 있는 빅딜을 통한 전 자학술정보의 입수, 오픈액세스 그리고 구글 학술검색은 지금까지 각각 별도의 주제로 논의 되었으나 이 연구에서는 세 가지 주제를 향후 학술정보의 생산, 유통 및 접근의 관점에서 연 계하여 분석함으로써 국내 대학도서관 사서 및 연구자에게 새로운 관점을 제시하고 구체적인 대안을 준비할 수 있게 한다.

이 연구는 여러 전자학술정보 가운데 전자 학술지에 초점을 맞추고 있으며, 국내 전자학 술지 보다는 해외전자학술지 및 학술지 논문 에 관하여 주로 논하고자 한다. 이러한 논의는 당연히 학술커뮤니케이션 시스템 전반에 관 한 검토를 요구하지만 본 논문에서는 해당 학 술정보의 생산, 유통 및 이용의 관점에서 국 내 대학도서관과 이용자들에게 보다 직접적인 영향을 미치는 요인에 대해 주로 분석하고자 한다.

\section{2. 빅딜 기반 전자학술정보 구독모형 평가}

\section{1 학술지 발간과 유통에 대한 개관}

1665년에는 Henry Oldenburg가 세계 최초 의 학술지라고 할 수 있는 Philosophical Transactions of the Royal Society of London을 창 간하면서 학술 연구의 결과를 학술지라는 독특 한 매체를 통해 발표하고 보급하는 것이 시작된 이후 현재까지 학술정보 출판, 특히 학술지의 기 본적인 구조에는 큰 변화가 없었다고 할 수 있다. 다만 최근 학술단행본과 비교해 학술지의 중 요성이 상대적으로 더 높아지고 있는 점, 전세계 적으로 수준 높은 학술지에 게재하고자 하는 개 인간, 기관간, 그리고 국가간 경쟁이 심화되고 있다는 점이 주요한 추세이다. 특히 학술지 논 문이 제출되고 심사되고 출판되는 기본적인 과 정에는 큰 변화가 없어 보인다. 하지만 1990년 대부터 본격적으로 시작된 인쇄학술지로부터 전 자학술지로의 전환으로 인해 학술지의 유통 및 이용에는 급격한 변화가 있었다. 특히 전자학술 지를 발행해서 유통시키는 출판사와 이용자를 대신해 다양한 학술지를 구입하여 제공하는 기 능을 수행해 온 도서관과의 거래에는 중대한 변 화가 나타났다.

현재 국내외를 막론하고 대다수의 도서관은 대부분의 학술지를 소수의 출판사로부터 수백 혹은 수천 종의 학술지를 묶음으로 구독하고 있 다. 또한 지속적인 학술지 가격에 대응하기 위 해 개별적으로 구독하는 대신 다양한 컨소시엄 (지역, 국가 단위 등)을 통해 구독하고 있다. 앞 서 언급했지만 국내 대학도서관의 경우 대부분 
의 전자학술지 및 학술데이터베이스를 KESLI 컨소시엄과 KERIS의 해외전자정보 컨소시엄 을 통해 구입하고 있다. 학술지의 경우 소수의 출판사의 과점현상이 심해지고 있다. 특히 대표 적인 인용색인인 Thomson Reuters사의 Web of Science데이터베이스에 포함된 학술지의 절 반이상이 Elsevier, Wiley-Blackwell, Springer, Taylor \& Francis, 그리고 SAGE에 의해 출판 되고 있다(Bosch \& Henderson, 2012). 학술지 가 수많은 학회를 통해 발간되고 있다는 점을 고려하면 이들 거대출판사의 시장 지배력은 매 우 크다고 할 수 있다.

도서관의 관점에서 보면 빅딜의 초기에는 기 존 인쇄학술지 구독 비용에 약간의 추가적인 비 용을 지불하면 이용자들이 절대적으로 선호하 는 전자학술지를 대량으로 입수할 수 있다는 점 에서 빅딜은 매력적인 자료입수 방법이 되었다. 또한 인쇄학술지를 입수, 관리 및 보존하는데 따르는 제반 비용, 인력 및 공간의 절감을 실현 할 수 있게 되었다. 국내의 대학도서관이 이용 자들에게 전자학술정보를 제공하는데 있어 해 외 유수대학과 비교가 가능해진 점을 고려하면 빅딜은 어쩌면 구세주와 같은 역할을 했다고도 볼 수 있다. 특히 대학의 교수 및 연구자들에게 시간과 공간의 제약 없이 다양한 전자학술정보 를 제공함으로써 빅딜은 국내 대학의 기본적인 연구환경을 획기적으로 개선하는데 기여했다.

1990년대 중반에 시작된 빅딜 형태의 전자학 술정보 구독모형은 이후 빠른 기간 동안 전세계 대학도서관으로 파급되어 약 15 년이 지난 지금 에는 다른 형태의 전자학술정보 구입 방식을 생 각할 수 없는 상황이 되었다. 전자학술지는 개 발 초기에 기존 비교 대상이 없어 적절한 가격
모형을 정하기가 어려웠고 특히 출판사 입장에 서 자료가 불법으로 쉽게 복사, 전파될 수 있는 점 때문에 가졌던 우려가 컸던 것을 생각하면 빅딜은 학술정보 유통에 있어서는 획기적인 변 화라고 할 수 있다.

\section{2 빅딜의 내용}

빅딜을 통한 전자학술지 구독가격은 초기에 기존의 인쇄학술지 구독가격을 기본으로 전자 접근비용을 추가하는 형태로 구독가격이 형성 되었다. 빅딜의 핵심적인 부분은 3 년 혹은 4 년 의 구독기간 동안 구입하는 도서관 혹은 컨소시 엄과 출판사와의 합의에 의해 고정된 연간 인상 률을 미리 정하는 것인데 통상 $5 \%$ 내외에서 결 정되었다. 이러한 미래 가격의 고정은 도서관과 출판사의 이해관계가 반영된 것이다. 도서관은 주어진 예산에 따라 비용을 지출하는데 사서들 은 도서관 자료구입비 중에서 가장 큰 비중을 차지하는 전자학술정보 구입비의 변동에 대한 불확실성을 가급적 없애는 편을 선호한다. 출판 사 입장에서도 몇 년 동안 회사의 매출을 보장 받을 수 있다는 점에서 이러한 구독방식을 원하 였다. 따라서 빅딜을 통한 전자학술정보의 유통 은 도서관과 출판사 모두에게 윈-윈(Win-Win) 이라고 보는 관점이 많다.

하지만 거듭된 국내 및 세계경제의 위기 가운 데 빅딜 초기의 이러한 매력은 구독가격이 매년 누적적으로 인상되면서 점차 줄어들고 오히려 우려의 목소리가 높아지고 있다. 학술지 및 학술 논문의 경우 대체성이 거의 없다는 점에서 일단 어떤 출판사의 전자학술지 묶음을 구독하게 되 면 실제적으로는 다른 출판사 제품으로 옮겨가 
기 매우 어렵다. 즉 이전이 거의 불가능하고 가 격적인 면이 아닌 이용자와의 관계에서 이전비 용(switching cost)이 매우 높다고 할 수 있다.

매년 학술지 가격 추이를 보고하는 Library Journal의 2012년도 자료에 의하면, Elsevier, Wiley, Springer를 포함한 5대 출판사의 전자 학술지 가격이 전년 대비 평균 $4.5 \%$ 인상되었 다고 한다. 또한 이들 학술지 출판사로부터 학 술지 논문을 구입해서 약 18,000 개의 전자학술 지 패키지를 구성해 도서관에 제공하는 $\mathrm{EBSCO}$ 사의 경우에도 전년 대비 가격이 $5.1 \%$ 인상되 었다고 조사되었다. 최근 발표된 대학도서관 예 산 관련 사서들을 대상으로 한 설문(EBSCO, 2012)에 따르면 응답자의 $69 \%$ 가 도서관 금년 예산이 예년과 같거나 감소했다고 보고했고, 내 년에도 금년과 예산이 비슷하다고 한 응답자는 $52 \%$, 감소할 것이라고 전망한 응답자는 $22 \%$ 였 다. 국내 대학도서관에 대해서는 비교 가능하고 신뢰할만한 통계가 없지만 가파르게 상승하는 전자학술정보의 구독가격을 충분히 감당할 수 있는 예산 증가는 매우 드물 것이라고 판단된다. 따라서 대학도서관들은 단행본이나 인쇄학술지 의 구입비 등을 줄이는 방식으로 전자학술지 가 격 인상분을 충당하고 있다.

미국의 연구중심 대학도서관협회(ARL: $\mathrm{As}^{-}$ sociation of Research Libraries) 의 2009년 통 계에 따르면 소속 도서관 113곳의 평균 전자정 보구입비는 전체 자료구입비의 약 $56 \%$ 로 이 수 치는 매년 증가하고 있다.2) 우리나라 대학도서 관의 경우에도 전체 자료구입비에서 해외전자정 보자료 구입비가 차지하는 비중이 2008년 28.2\%,
2009년 35.3\%, 2010년 38.1\%, 2011년 40.6\%, 그리고 2012년 44.7\%로 나타났다. 3 ) 따라서 전 자학술지 가격 인상은 국내의 대학도서관과 미 국의 대규모 대학도서관 모두의 미래에 심각한 위협이 될 것으로 보인다.

\section{3 빅딜 구독모형의 문제점}

빅딜의 문제점은 통상 3 가지로 요약된다. 첫 째, 도서관 예산상의 문제이다. 소수의 출판사 계약에 도서관 자료구입비의 상당 비율이 매이 게 되며, 일년 구독비의 선지급, 다년간 가격 상 승 보장을 하게 되는 점은 도서관 예산 운용을 어렵게 한다. 지속적인 전자학술지 가격인상은 다른 자료구입비 비중을 잠식하고 도서관 예산 이 삭감되는 경우 심각한 상황으로 치닫게 될 수 있다는 점이다.

둘째, All-or-Nothing 이라는 경직된 계약구 조의 문제이다. 물론 출판사의 전자학술지를 분 야별로 세분화해서 따로 구독하거나, 기구독 학 술지를 유지하는 조건을 없애고, 이용자 규모에 따라 차별적인 가격을 적용하는 등의 다양한 계 약 조건이 생기고 있다(신은자, 2007). 하지만 개별 학술지를 선택할 수 없다는 점은 여전하 다. 출판사의 입장에서는 매년 6-7\%의 새로운 논문이 추가되고 있고, 이용통계에 근거해 다운 로드 논문 하나당 구독비용이 지속적으로 감소 하고 있다는 점 때문에 가격인상이 불가피하다 는 논리를 제시한다(Poynder, 2011a). 도서관 의 입장에서는 단위 논문당 구독비용이 감소하 고 있는 것은 사실이지만 어느 시점에 이르면 이

2) 해당 자료는 ARL 웹사이트에서 추출하였다. http://www.arl.org/stats/annualsurveys/arlstats/preveds.shtml

3) 해당 자료는 교육과학기술부 학술정보통계시스템에서 추출하였다. http://www.rinfo.kr/ 
수치는 정체될 것이며 결국 사용하지 않는 논문 에 대해서도 계속 비용을 내야하는 불합리한 상 황을 제기하지만 아직까지는 출판사가 주도권 을 가지고 있는 것으로 판단된다. 따라서 빅딜 은 도서관의 필요에 따라 장서를 유연하게 조정 할 수 있는 능력에 심각한 위협이 되고 있다.

셋째, 소수의 출판사에 의한 독과점의 형성 문제이다. 전자학술지의 등장은 대형 출판사들 이 자사 학술지를 늘림으로써 비용을 절감하고, 시장지배력을 강화할 수 있는 절호의 기회가 되 었다. 따라서 지난 15 년간 지속적으로 출판사 간 인수/합병이 활발하게 전개되어 소규모 출 판사는 쉽게 도태될 수 있는 환경이 되었다. 물 론 Project MUSE, SWETS, BioONE의 경우 처럼 소규모 출판사들이 자체적으로 컨소시엄 을 구성함으로써 빅딜에 참여하고 있다. 하지만 학술지 출판시장에서 대규모 출판사의 영향력 과 시장지배력은 급속하게 커졌다. 이러한 학술 지 출판 및 유통 생태계의 변화는 대학도서관에 게 장기적으로 이런 시스템이 지속될 수 있는가 에 대한 의문을 가지게 한다.

빅딜 출판사들은 도서관들이 지속적으로 비 용에 대한 불만을 제기하면서도 결국에는 가격 협상에 응했고 인상된 가격을 수용하였으며 앞 으로도 도서관이 그렇게 할 수 있을 것이며, 학 술연구의 가장 핵심적인 기반의 하나인 학술정 보 구입을 위해 대학이 추가적인 지출을 해야 할 것이라고 역설한다. 동시에 기존의 빅딜 가 격모형에 이용자 규모(Full-time equivalent), 대학의 학과 분포, 그리고 과거의 이용실적 등 을 고려한 수정된 모형으로 전환하고 있다. 하 지만 근본적인 빅딜의 모습은 여전히 건재하다 고 할 수 있다.
도서관 입장에서는 이제는 예전의 인쇄학술지 의 경우처럼 기관의 필요에 따라 전자학술지를 개별적으로 선택해서 구독할 수 있는 상황으로 갈 수 없다. 따라서 예산상의 문제만 아니라면 대 부분의 도서관은 현재의 빅딜 형태의 구독모형을 선호할 것이다. 일면 불합리해 보이는 다년계약 도 불확실성의 요소를 제거한다는 점에서 받아 들일 수 있는 것이다. 도서관들이 빅딜에서 벗어 나기 어려운 또 한가지 점은 이용자 때문이다. 대 학도서관은 이용자를 대신해 높은 가격의 학술 지를 구독하여 제공하고 있다. 대부분의 연구자는 도서관의 예산 문제에는 전혀 관심이 없다. 따라 서 현재 손쉽게 이용하고 있는 전자학술지가 어느 순간 없어진다는 것은 받아들이기 어렵다. 특히 자신의 연구 분야의 전자학술지, 본인의 논문이 실리는 학술지의 지속적인 구독을 원하고 있다.

\section{4 빅딜의 균열 가능성 및 대안}

이러한 상황을 고려할 때 비록 빅딜의 여러 문제에도 불구하고 당분간 빅딜을 대체할만한 대안이 도서관에게도, 출판사에게도 없어 보인 다. 물론 이러한 상황이 얼마든지 바뀔 수 있음 을 보여주는 몇 가지 사례가 있다.

University of Washington은 2010년 상당 한 규모의 도서관예산 삭감으로 인해 Springer 출판사의 1,200 개 학술지 패키지에 대한 구독 계약 갱신을 포기하는 것을 포함한 총 2,800여 개의 온라인 및 인쇄학술지에 대한 구독을 전 격적으로 취소하는 조치를 취했다(UW Today, 2010). 물론 University of Washington만 이런 조치를 취했다고는 볼 수 없다. 하지만 이 대학 의 경우 매우 공개적으로 이런 결정을 외부에 알 
렸고 결정의 근거로 빅딜의 문제점을 지적했다 는 점에서 눈여겨볼 필요가 있다. 예산의 문제 가 지속적으로 유지된다면 다른 도서관들도 이 처럼 하지 않으리라는 보장이 없고, 만약 이런 결정의 도미노가 일어난다면 빅딜 구조의 유지 에 균열이 생기는 것이다.

다른 한 가지 사례는 2011년에 영국의 연구중 심 대학연합인 Research Libraries UK(RLUK) 가 Elsevier와 Wiley-Blackwell 두 빅딜 출판 사에게 2012년 초에 갱신되는 계약에 대해 2007 년 수준으로 가격을 낮추지 않으면 계약을 하 지 않겠다고 최후통첩을 한 사례이다(Poynder, 2011b). 이는 약 $15 \%$ 의 가격할인을 의미하는 것이다. RLUK는 두 출판사가 협상에 응하지 않을 경우 back file 구독과 원문복사 서비스를 통해 이용자들에게 학술지 논문을 제공하겠다 는 대안까지 공표를 했다. RLUK와 출판사간의 수개월에 걸친 대치는 2011년 12월에 협상이 타 결되면서 일단락되었다. 비밀보장 조건4) 때문 에 구체적인 내용은 알려지지 않았지만 RLUK 는 새로운 계약기간(5년) 동안 총 \$31.4 Million 을 절감하게 되었다고 발표했다(Rapp, 2011). RLUK가 요구한 $15 \%$ 의 할인은 아니더라도 적 어도 $10 \%$ 이상의 할인을 관철했다는 것으로 짐 작할 수 있다. RLUK의 사례는 도서관들이 연 합해 강경한 자세로 가격 협상에 임하는 경우 상당한 가격할인을 받을 수 있다는 점에서 교훈 이 되는 반면, 수년 내로 원래의 가격으로 돌아 갈 수 밖에 없다는 점에서 빅딜의 해체라기 보
다는 시간을 버는 조치로 보인다.

국내 대학도서관의 경우 빅딜을 전세계 어느 나라 대학도서관보다 적극적으로 도입하였으며 이는 KESLI에 참여하는 컨소시엄의 규모와 종 류, 참여하는 도서관의 규모(2012년 566개 기 관 참여, $50 \%$ 가 대학도서관, 총 컨소시엄의 수 118 개) 가 보여준다. 빅딜이 제공하는 방대한 전 자학술정보에 대한 접근, 관리의 용이성 등의 장점으로 인해 상대적으로 열악한 환경에 있던 국내 대학도서관들은 빠른 시간 안에 빅딜에 깊 숙하게 참여하게 되었다. 특히 우리나라의 경우 KISTI와 KERIS와 같은 공공기관이 컨소시엄 구축에 중개자 역할을 하고, 공동구매한 자료의 원활한 이용을 위해 NDSL, RISS와 같은 국가 학술정보망에 해당 컨텐츠를 통합하는 매우 깊 은 단계에서 빅딜에 관여하고 있다. 이와 같은 통합정보의 제공은 연구자들에게는 한 곳에서 다양한 학술정보를 제공함으로써 효율성을 제 고하는 측면이 분명히 있지만(한국과학기술정 보연구원, 2010), 한편으로는 빅딜 형태의 구매 모형이 더 이상 유효하지 않을 수 있다는 가능 성을 고려하면 위험한 측면도 있다.

현재의 상황에서 보면 앞으로 당분간 빅딜이 국내 대학도서관에게 지속적으로 유효한 해외 학술정보 구독모형으로 남아있을 것으로 보인 다. 왜냐하면 빅딜을 대체할만한 새로운 유통 모형이 아직까지는 확실하게 제시되지 못하고 있기 때문이다. 현재 거의 유일하게 시행되고 있 는 빅딜의 대안은 PDA(Patron Driven Acqui-

4) 빅딜을 포함한 대학도서관의 학술정보 구독계약은 당사자 이외에는 알려지지 않게 비밀보장 조건이 포함되어 있 다. University of California Santa Barbara의 경제학과 교수인 Ted Bergstorm은 2009년에 28개 주, 36개 대학도 서관으로부터 구독계약을 넘겨받았다. 이에 대해 Elsevier, Springer 출판사 등이 법정 소송을 제기하였으나 법원은 도서관과 Bergstorm편을 들었다. http://www.econ.ucsb.edu/ tedb/Journals/BundleContracts.html 
sition)라고 불리는 pay-per-view 방식의 구독 이다. 현재 Elsevier, Wiley-Blackwell 등 주요 출판사가 $\mathrm{PDA}$ 방식의 구독 조건을 제시하고 있다. $\mathrm{PDA}$ 는 다음 두 가지 방식으로 실현된다 (Weicher \& Zhang, 2011). 첫째 방식은 도서 관이 전자학술지를 구독하지 않고 모든 논문을 access token 즉 건당 구매하는 것이다. 두 번째 방식은 도서관이 미리 해당 출판사의 전자학술 지 중에서 핵심학술지를 선택하여 해당 학술지 논문에 대해서는 기존에 하던 것처럼 무제한 접근을 하고 나머지 학술지 논문에 대해서는 건당으로 구매하는 방식이다. 최근에 PDA 방 식의 학술지 구독에 대한 실험이 보고되고 있 지만(Carr \& Collins, 2009; Chamberlain \& MacAlpine, 2008; Weicher \& Zhang, 2011) 이 방식이 앞으로 빅딜을 전반적으로 대체할 수 있을지에 대한 의문은 여전히 남아있다.

$\mathrm{PDA}$ 방식의 구독은 무엇보다 대학도서관에 지금까지는 미미했던 예산상의 불확실성을 주 고, access token의 발급, 통제 등과 관련된 기 술적, 관리적 문제를 발생시킨다. PDA 방식의 학술지 구독을 도입하는 도서관은 학술지 논문 사용을 세밀하게 모니터링 해야 하는 부담이 있 으며, 무엇보다 이용자에게 이런 방식의 필요성 및 이용방법에 대해 안내 및 지원을 해야 한다. 보다 궁극적인 문제는 정보 입수와 관련된 도서 관의 역할 변화이다. PDA 구독방식은 사서의 정보 및 자료 선별 의사결정을 이용자에게 옮기 는 것이다. 또한 빅딜 형태로의 구독방식 전환 을 통해 도서관의 자료 및 정보에 대한 영속적 인 접근 기능이 약화되기는 했지만 $\mathrm{PDA}$ 구독 방식은 도서관의 이 기능에 치명적인 위협이 될 것으로 우려된다(Carr, 2009/2010).
물론 PDA구독방식을 도입하는 도서관의 주 요 관심사는 예산의 절감이다. 즉 이용하지 않 는 학술지 논문에 대해서는 비용을 부담하지 않 고 이용자의 직접적인 요청이 있을 경우에만 비 용을 지출하려는 것이다. 따라서 향후 예산의 압박이 심한 도서관은 $\mathrm{PDA}$ 구독방식을 실험 적으로 도입하는 것을 고려할 수 있으며 일괄 적으로 구독방식을 변경하기 보다는 점진적인 도입이 현명한 대처방안이 될 것이다. 한편으로 는 PDA 구독방식은 예산의 문제로 전자학술지 구독을 할 수 없었던 소규모 도서관에게는 매력 적인 방안이 될 수 있다.

결론적으로 빅딜의 지배적인 위치는 당분간 유지될 것으로 전망된다. 일부 대학도서관이 빅 딜을 취소하고 $\mathrm{PDA}$ 구독방식을 채택하겠지만 10 년 내에 빅딜 방식을 통한 전자학술지 입수 방식 자체가 교체될 가능성은 낮은 것으로 평가 할 수 있다. 하지만 현재의 상황에 가장 위협이 되는 변수는 대학도서관의 예산 문제이다. 특히 앞에서 살펴보았듯이 국내외 대학도서관에서의 전자정보구독비 비중이 전체 자료구입비의 절 반 혹은 그 이상을 차지하고 있어 향후 지속적 인 가격 인상은 대학도서관의 예산 운용에 큰 타격이 될 것으로 전망된다.

\section{3. 대안적인 학술지 출판 및 유통을 위한 오픈액세스}

\section{1 오픈액세스 개관}

오픈액세스라는 용어는 2001년 12월 헝가리 부다페스트에서 비교적 소규모로 모인 Open 
Society Foundation 회의를 통해 2002년 Budapest Open Access Initiative(BOAI) 선언에서 처음으로 사용되었다. 물론 $\mathrm{BOAI}$ 이전에도 연 구자들과 도서관계에서 연구성과물, 특히 학술 논문의 이용 및 접근 장벽을 제거하려는 노력은 지속적으로 있었다. 하지만 2000년대 들어, 특 히 $\mathrm{BOAI}$ 선언을 통해 보다 체계적이고 활발한 운동으로 전개되고 있다. $\operatorname{Suber}(2004,2012)$ 에 따르면 오픈액세스란 전자학술논문을 사용하 는데 제한을 주는 가격 장벽(유료구독, 라이선 싱 비용, pay-per-view 비용 등) 과 권한 장벽 (대부분의 저작권 및 라이선싱 제한)을 없애는 것이는 것이다. 일반적으로 오픈액세스란 동료 심사를 받는 학술논문 중에서 전자파일의 형태 로 된 것에 대한 제한 없는 접근을 의미한다. 최 근에는 오픈액세스의 철학적인 기반이 다른 형 태의 학술자료인 단행본(Open Access Monograph), 대학교재(Open Textbook), 학술데이터 (Open Data) 를 넘어 강의자료(Open Course Ware, $\mathrm{OCW}$ ) 등으로까지 확산되고 있다.

오픈액세스를 시행하고 확산하려는 개인과 단체는 여러 가지의 복합적인 동기를 가지고 있 다. 인터넷을 통해 저렴한 가격으로 지식을 효 율적으로 전파하기 위한 동기, 학술지 가격의 급격한 상승에 대한 반작용으로서의 동기, 학술 지의 상업화/과점화에 대한 비판으로 학문연구 및 지식 사용의 공공성을 강조하는 것이 그것 이다. 오픈액세스를 실행하는 구체적인 방법으 로 $\mathrm{BOAI}$ 선언은 저자들이 저작권의 제한이 없 는 논문파일(출판전 원고 등)을 연구자 개인 홈 페이지, 주제 분야 혹은 기관 저장소(archives, institutional repositories) 등에 올려 사용하게 하는 방법(뒤에 Green OA로 명명)과 새로운
$\mathrm{OA}$ 학술지를 창간하는 방법(뒤에 Gold OA로 명명)을 제시하고 있다(BOAI, 2002). Gold OA 학술지 목록을 수록하고 있는 the Directory of Open Access Journals(DOAJ)에는 2012년 11월 초 현재 8,339개의 학술지가 포함되어 있 다. 비교를 위해 전세계 동료심사 학술지 규모 는 UlrichsWeb이라는 데이터베이스에서 제공 하고 있는데 Morrison(2012)의 연구에 의하면 2011년 말 현재 26,746개가 있는 것으로 추정되 고 있다.

Gold OA 학술지의 경우, 출판비용을 충당하기 위해 논문처리비용(Article Processing Charge, $\mathrm{APC})$ 을 저자에게 요구하는 경우와 그렇지 않 은 두 가지 학술지 형태가 있다. 실제로는 Green $\mathrm{OA}$ 와 Gold $\mathrm{OA}$ 두 방법에 대한 다양한 변형이 시도되고 있다. 예를 들어, Elsevier나 Springer 와 같은 상업출판사에서는 저자가 원하면 $\mathrm{APC}$ 를 지불하고 본인의 논문을 $\mathrm{OA}$ 로 요청할 수 있다. 이런 형태의 오픈액세스는 Hybrid OA로 불린다. 하지만 상업출판사의 Hybrid OA 경우 $\mathrm{APC}$ 가 대개 $\$ 3,000$ 수준으로 높아 저자들이 참여하는 비율이 $1-2 \%$ 에 그치는 것으로 보고 되고 있다(Björk, 2012). 또한 정부의 연구지원 을 통해 수행된 연구에 대해서 비록 상업출판 사의 유료 학술지에 출판되었더라도 6-12개월 이 지나면 해당 출판사 웹사이트 혹은 PubMed Central, HighWire Press 등과 같은 경로를 통 해 오픈액세스로 제공되는 경우도 있는데 이런 논문은 Delayed OA로 불린다.

\section{2 파괴적 변화로서의 오픈액세스 평가}

빅딜은 유료 전자학술정보를 출판사와 대학 
도서관 사이에서 효과적으로 유통시키는 도구 이다. 하지만 만약 대부분의 학술논문이 여러 형태의 오픈액세스 논문으로 출판된다면 빅딜 이라는 도구 자체가 무력화되는 결과를 낳게 될 것이다. 따라서 이 논문에서는 오픈액세스 논문 이 현재 발간되고 있는 학술지 논문 중에서 어 느 정도 비중을 차지하고 있는지 최근에 발표된 연구를 중심으로 살펴보고자 한다. 물론 전세계 에서 발행되는 학술지 논문의 정확한 규모를 파 악하는 것은 불가능하다. 또한 다양한 경로로 발간되고 유통되는 오픈액세스 학술논문 규모 를 추정하는 것도 쉬운 일은 아니다. 하지만 최 근 발표되고 있는 관련 연구들은 어렴풋이나마 오픈액세스가 학술논문 시장에 어느 정도 수준 에서 침투하고 있는지 보여줌으로써 그것의 획 기적인 변화 가능성을 보여줄 수 있다.

이런 논의에서 간과해서는 안 될 사항은 학술 지 논문의 질에 관한 것이다. 학술지와 논문의 수준 및 질을 평가하는 것은 매우 복잡하고 어려 운 일이지만 일반적으로 권위 있는 인용데이터 베이스인 Thomson Reuters사의 Web of Science(SCI, SSCI \& A\&HCI 등) 와 Elsevier사 의 SCOPUS에 포함된 학술지는 어느 정도 품 질수준을 가지고 있는 것으로 받아들여지고 있 다. 따라서 현재 출판되고 있는 오픈액세스 논 문의 규모를 추정하고 이들 논문 중에서 양대 인용데이터베이스에 포함된 비율을 측정하게 되면 현재 학술논문시장에서 오픈액세스의 폭 발력이 어느 수준인지 가늠할 수 있게 된다.

Laakso et al.(2011)은 1993년부터 2009년까 지의 오픈액세스 출판 추이를 연구하였다. 이 연구는 대표적인 오픈액세스 학술지 목록인 the Directory of Open Access Journals(DOAJ)
에 수록된 학술지를 대상으로 대규모 학술지 44 종과 중소규모 학술지 519종, 총 563개의 샘 플을 추출하고 여기에 $\mathrm{OA}$ 운동 초기에 선구적 인 역할을 한 학술지 304 종을 추가한 학술지 목 록을 대상으로 조사하였다. 이 연구 결과에 의 하면 OA 출판은 2000 년도부터 연평균 약 $18 \%$ 의 학술지, $30 \%$ 의 학술논문의 증가를 보이고 있다. 2009년에는 전체 동료심사 학술지 논문 중에서 약 $7.7 \%$ 가 오픈액세스로 출판되고 있 다고 추정되었다.

Laakso et al.의 연구는 Gold OA 학술지 논문 을 대상으로 수행된 반면 Gargouri et al.(2011) 가 수행한 연구는 Gold OA뿐 아니라 Green $\mathrm{OA}$ 논문의 증가도 연구대상으로 삼았다. 이 연구는 먼저 14 개로 구분된 학문 영역 각각에 대해 2005년부터 2010년의 기간 동안 연간 약 1,300 개의 논문을 Web of Science 데이터베이 스에서 추출하였다. 총 107,052 개의 논문이 샘 플로 사용되었다. 이 중에서 오픈웹을 통해 논 문 전문이 오픈액세스 형태로 접근할 수 있는 수치를 웹트롤링(Web Trawling) 방식으로 측 정하였는데 약 200 개의 소규모 표본 추출을 통 해 측정한 웹트롤링 방식의 정확성은 $98 \%$ 로 보 고되었다. 결과를 살펴보면 2011년 현재 해당 논문 중에서 오픈액세스로 접근할 수 있는 논문 의 비율은 약 $24 \%$ 로, 분야별로는 예술분야가 $10 \%$ 로 가장 낮고 수학분야가 $45 \%$ 로 가장 높 게 조사되었다. 연간 오픈액세스 논문의 증가율 도 조사되었는데 1998년에 14\%에서 2006년에 는 $21 \%$ 증가하고 있는 것으로 나타났다.

Gargouri et al.의 연구에서 오픈액세스로 접 근 가능한 논문 $24 \%$ 는 Green OA가 $21 \%$, Gold $\mathrm{OA}$ 가 $2.4 \%$ 로 구성되어 있었다. Biomedical 분 
야는 Gold OA가 $8 \%$ 로 가장 높은 반면(대부 분 1-2\% 수준) Green $\mathrm{OA}$ 비중은 $6 \%$ 로 상대 적으로 매우 낮았으며, 수학 분야는 Green $\mathrm{OA}$ 비율이 $43 \%$ 로 매우 높지만 Gold OA는 $2 \%$ 로 매우 낮은 것으로 조사되었다. 따라서 분야별 로 Gold $\mathrm{OA}$ 와 Green $\mathrm{OA}$ 의 비중이 상대적으 로 많이 차이가 난다. 이런 결과가 나온 이유는 biomedical 분야는 Public Library of Science (PLoS) 나 BidMed Central과 같은 대표적인 Gold OA 출판이 매우 발달해 있는 반면 수학 분야의 경우 대표적인 주제분야 preprint server 인 arXiv 서비스를 통해 상당수의 논문이 오픈 액세스 형태, 즉 Green OA로 제공되고 있기 때 문인 것으로 보인다.

Laakso \& Björk(2012)는 최신 연구에서 2000년부터 2011년까지 OA 논문수 증가를 조 사하고 $\mathrm{OA}$ 논문이 양대 인용데이터베이스에 어느 정도 수준에서 색인되고 있는지를 보였다. 이 연구는 2011년에 DOAJ에 포함된 7,372종의 오픈액세스 학술지를 대상으로 총 787 개의 학 술지를 표본으로 추출하였다. 이 중에는 연간 200 개 이상의 논문을 게재하는 대규모 학술지 103 개와 200개 미만 논문을 게재하는 학술지 총
7,269개 중에서 추출된 684 개의 학술지가 포함 되어 있다. 〈표 1〉은 이 연구의 주요 결과를 요 약하고 있다.

Laakso \& Björk(2012)의 연구는 Gargouri et al.(2011)의 연구와는 달리 주로 Gold OA와 유료학술지 중에서 Delayed 및 Hybrid OA로 제공되고 있는 논문을 조사한 것으로 Green $\mathrm{OA}$ 에 해당하는 부분은 빠져있다. 〈표 1〉을 보면 오 픈액세스 학술지 논문수는 2000년부터 2011년 까지 평균 약 $30 \%$ 증가하고 있으며 오픈액세스 논문 유형별로 보면 $\mathrm{APC}$ 가 있는 Gold OA 학술 지의 증가세가 가장 높고(연평균 $65 \%, 2003$ 년 부터 계산하면 $45 \%)$, 유료학술지 중 OA 컨텐 츠의 증가율은 상대적으로 낮다 $(22 \%, 2003-2011$ 에는 $18 \%$ ). 특이한 점은 2011년도에 발표된 전 체 오픈액세스 논문(340,130) 중에서 Biomedicine 분야의 논문이 120,900 건으로 $35 \%$ 의 높은 비중 을 보이고 있다. 이 점은 Gargouri et al.(2011) 의 연구 결과와 일맥상통하는 부분이다.

Laakso \& Björk는 여러 형태의 오픈액세스 논문이 Scopus와 Web of Science 인용데이터 베이스에 포함된 비중도 조사하였는데 결과는 〈표 2〉에 요약되어 있다. 이 데이터 역시 Green

〈표 1〉오픈액세스 논문 및 학술지 수치 추정

\begin{tabular}{c|c|r|r|r|r|r|r|r|r|r|r|r|r}
\hline & & 2000 & 2001 & 2002 & 2003 & 2004 & 2005 & 2006 & 2007 & 2008 & 2009 & 2010 & 2011 \\
\hline \multirow{2}{*}{$\begin{array}{c}\text { APC가 있는 } \\
\text { Gold OA }\end{array}$} & 논문 & 795 & 2,332 & 4,936 & 6,247 & 7,531 & 12,143 & 17,256 & 25,949 & 40,689 & 54,296 & 90,932 & 136,264 \\
\hline \multirow{2}{*}{$\begin{array}{c}\text { APC각술지 없는 } \\
\text { Gold OA }\end{array}$} & 53 & 120 & 167 & 189 & 256 & 344 & 425 & 630 & 950 & 1,239 & 1,494 & 1,824 \\
\cline { 2 - 15 } & 학술지 & 5,445 & 10,690 & 13,844 & 17,238 & 20,106 & 26,626 & 33,067 & 38,991 & 46,362 & 62,521 & 81,421 & 93,513 \\
\hline \multirow{2}{*}{$\begin{array}{c}\text { 유료학술지 } \\
\text { OA 컨텐츠 }\end{array}$} & 논문 & 14,461 & 23,095 & 27,234 & 39,814 & 51,614 & 66,494 & 75,486 & 86,691 & 100,393 & 108,793 & 116,003 & 110,353 \\
\cline { 2 - 13 } & 학술지 & 357 & 550 & 630 & 847 & 1,106 & 1,375 & 1,539 & 1,819 & 2,011 & 2,149 & 2,170 & 2,395 \\
\hline \multirow{2}{*}{ 전체 } & 논문 & 20,702 & 36,117 & 46,013 & 63,299 & 79,253 & 105,262 & 125,809 & 151,630 & 187,444 & 225,610 & 288,357 & 340,130 \\
\cline { 2 - 12 } & 학술지 & 744 & 1,154 & 1,410 & 1,841 & 2,368 & 2,991 & 3,502 & 4,243 & 5,010 & 5,788 & 6,213 & 6,713 \\
\hline
\end{tabular}

출처: Laakso, M \& Björk, B-C. (2012). Anatomy of open access publishing: a study of longitudinal development and internal structure. BMC Medicine. 10:124. 
〈표 2〉OA 논문 형태별 인용데이터베이스 포함 비율

\begin{tabular}{c|l|r|r|r|r|r|r|r|r}
\hline \multicolumn{2}{c|}{} & \multicolumn{2}{|c|}{2008} & \multicolumn{2}{|c|}{2009} & \multicolumn{2}{|c|}{2010} & \multicolumn{2}{|c}{2011} \\
\hline \multirow{4}{*}{ SCOPUS } & Total articles & $1,469,286$ & $100 \%$ & $1,550,413$ & $100 \%$ & $1,588,636$ & $100 \%$ & $1,658,643$ & $100 \%$ \\
\cline { 2 - 10 } & Full OA & 118,751 & $8.10 \%$ & 133,817 & $8.60 \%$ & 163,670 & $10.30 \%$ & 181,706 & $11 \%$ \\
\cline { 2 - 10 } & Hybrid OA & 4,718 & $0.30 \%$ & 8,095 & $0.50 \%$ & 10,135 & $0.60 \%$ & 12,089 & $0.70 \%$ \\
\cline { 2 - 10 } & Delayed OA & 78,054 & $5.30 \%$ & 82,271 & $5.30 \%$ & 81,404 & $5.10 \%$ & 85,714 & $5.20 \%$ \\
\cline { 2 - 10 } & Total OAarticles & 201,523 & $13.70 \%$ & 224,183 & $14.50 \%$ & 255,209 & $16.10 \%$ & 279,509 & $16.90 \%$ \\
\hline \multirow{4}{*}{$\begin{array}{l}\text { Web of } \\
\text { Science }\end{array}$} & Total articles & $1,154,803$ & $100 \%$ & $1,203,692$ & $100 \%$ & $1,235,202$ & $100 \%$ & $1,294,051$ & $100 \%$ \\
\cline { 2 - 10 } & Full OA & 76,537 & $6.60 \%$ & 85,852 & $7.10 \%$ & 103,514 & $8.40 \%$ & 116,192 & $9.00 \%$ \\
\cline { 2 - 10 } & Hybrid OA & 3,774 & $0.30 \%$ & 6,476 & $0.50 \%$ & 8,108 & $0.70 \%$ & 9,671 & $0.70 \%$ \\
\cline { 2 - 10 } & Delayed OA & 76,076 & $6.60 \%$ & 80,338 & $6.70 \%$ & 79,058 & $6.40 \%$ & 83,420 & $6.40 \%$ \\
\cline { 2 - 9 } & Total OA articles & 156,387 & $13.50 \%$ & 172,666 & $14.30 \%$ & 190,680 & $15.40 \%$ & 209,283 & $16.20 \%$ \\
\hline
\end{tabular}

$\mathrm{OA}$ 에 해당하는 논문은 포함되지 않았다.

〈표 2〉를 보면 2011년 기준으로 Gold OA 논 문이 Scopus에 포함된 전체 논문 중에서 차지 하는 비율은 $11 \%$, Web of Science에서는 9\% 의 비율을 보이고 있는 것으로 조사되었다. 여기 에 유료 학술지 논문 중에서 저자들이 APC 비 용을 지불한 $\mathrm{OA}$ 논문(Hybrid $\mathrm{OA}$ ) 과 발간 후 12개월 내로 오픈액세스로 전환되는 Delayed $\mathrm{OA}$ 논문수를 합하면 $\mathrm{OA}$ 컨텐츠의 비중은 각 각 $16.9 \%$ 와 $16.2 \%$ 로 높아진다. 주목할 점은 성 장증가율에서 Hybrid OA나 Delayed OA보다 Gold OA가 더 높다는 점이다. 앞서 조사된 바 대로 생물학, 의학분야의 활발한 Gold OA 학술 지 창간에 힘입은 것으로 추정된다.

지금까지 살펴본 오픈액세스 출판과 관련된 계량적인 연구들을 종합하면 아직도 전세계에서 출판되는 심사학술지(peer-reviewed journals) 의 약 $20 \%$ 정도가 오픈액세스로 출판되고 나머 지 80\%는 유료학술지 즉 Toll Access로 출판, 유통되고 있다. 하지만 오픈액세스 출판이 매년 빠른 성장세를 보이고 있음은 향후 이러한 구도 에도 중대한 변화가 있을 수 있음을 시사한다.
실제로 이용자들이 검색엔진을 통해 무료로 이 용 가능한 학술지 논문의 비중은 Green OA의 비중을 감안하면 이보다 더 높을 것으로 판단된 다. 현재까지의 조사된 데이터로는 오픈액세스 가 학술출판의 주류 모델로 가기 위한 중대한 분기점(threshold) 을 넘었다는 결론을 내릴 수 는 없다. 하지만 분야별로 이미 오픈액세스 출 판 모형이 상업출판을 위협하고 있는 경우(예: 생물학, 의학분야) 도 있다. 따라서 대학도서관 사서는 향후 오픈액세스 출판 동향과 특히 분야 별 오픈액세스 접근 도구의 발달을 주목할 필요 가 있다.

\section{4. 대안적인 학술정보 접근도구 로서의 구글 학술검색}

\section{1 구글 학술검색 개관}

현재 대학도서관은 이용자들이 방대한 학술 정보를 다양하게 접근하고 사용할 수 있도록 각 종 데이터베이스를 제공하고 있으며 빅딜은 이 
런 데이터베이스를 보다 효율적이고 낮은 가격 으로 입수할 수 있는 구독모형으로 자리잡았다. 대부분의 학술연구자는 도서관이 제공하는 자 기 분야의 전문 학술데이터베이스에 수시로 접 속해서 해당 분야의 최신 연구동향을 파악하고 진행하거나 계획하는 연구와 관련있는 학술논 문을 검색한다. 또한 많은 대학도서관은 구독하 고 있는 다양한 학술정보자원을 이용자가 통합 적으로 검색할 수 있도록 추가적인 지출을 통해 federated 검색 혹은 discovery 도구를 제공하 고 있다. 하지만 동시에 대부분의 학생과 일부 연구자는 사용하기 편리한 네이버나 구글같은 일반 검색엔진을 이용해 본인의 학습이나 연구 에 필요한 정보를 얻고 있는 것도 사실이다. 하 지만 일반검색엔진 시스템의 결과는 일부 학술 관련 내용이 포함되어 있기는 하지만 일반 웹 페이지, 개인 블로그, 상업 광고 등이 많이 포함 되어 있다는 단점이 있다. 전세계 검색엔진 시 장에서 주도적인 지배력을 가진 구글은 2004년 11월에 Google Scholar라는 서비스(국내에는 구글 학술검색으로 서비스)를 시작하였다. 구글 학술검색은 연구자 개인 홈페이지, 주제 및 기 관저장소(repositories), 출판사 등으로부터 학 술논문과 관련된 정보 및 원문을 수집, 제공하 고 있다. 아직까지는 구글 학술검색을 통해 접 근할 수 있는 학술지 논문이 비교적 최근 발행 된 논문에 제한되고 있으나, 논문의 피인용횟 수5) 및 저자 개인별 $\mathrm{h}$ 지수 등을 보여주는 등 인용데이터베이스로서의 기능도 제공하고 있다.
2009년 10월에 수행된 미국 University of California Santa Cruz의 이메일 조사(Hightower \& Caldwell, 2010)에 의하면 자연과학 및 공학 계열 교수, 연구자, 대학원생 이용자가 가장 많 이 이용하는 데이터베이스는 Web of Science (41.6\%) 였으며 PubMed(21.5\%)와 Google Scholar $(18.7 \%)$ 가 그 뒤를 이었다. 응답자의 $83 \%$ 가 Google Scholar를 사용한 경험이 있으 며 추가로 $13 \%$ 의 응답자는 Google Scholar를 사용해 보겠다고 하였다. 구글 학술검색은 검색 의 용이성, 속도면에서 선호되었으나 다른 데이 터베이스와 비교해서 검색결과의 질에 대해서 는 신뢰성이 낮았다.

\section{2 파괴적 변화로서의 구글 학술검색 평가}

구글 학술검색에 대한 대학도서관 사서의 관 심은 크게 두 가지이다. 첫째는 구글 학술검색 의 검색 기능이 도서관에서 제공하고 있는 학술 데이터베이스와 비교해서 어느 정도인지이다. 다수의 학술정보 이용자들이 사용하고 있는 도 구이므로 사서 자신들도 검색 기능을 이해하고 필요에 따라서는 이용교육에도 포함시키기 위 해서이다. 둘째는 과연 구글 학술검색이 기존의 학술 데이터베이스를 대체할 수 있을 것인가이 다. 대학도서관에서는 상당한 비용을 들여 데이 터베이스를 도입하고 이용자들에게 다양한 방 법으로 사용을 촉진시키고 있는데, 구글 학술검

5) 구글 학술검색에서 논문의 피인용횟수는 현재 해당 논문이 2007-2011년의 기간 동안에 받은 인용수로 제한되어 있다. 예를 들어 어떤 저자의 1999 년 논문이 있고 그 논문이 인용된 횟수가 10 회라고 표시되었다면 그 논문이 2007년부터 2011년까지 타논문에 의해 인용된 횟수가 그것이라는 의미이지 해당 논문이 1999년 발간부터 현재 까지 받은 전체 인용회수가 아니다. 
색이 상업 데이터베이스를 충분히 대체할 수 있 다면 예산 문제를 겪고 있는 도서관으로서는 비 록 단기적이기는 않겠지만 고려해 볼 사항이다. 이런 이유로 2005 년부터 구글학술검색의 검색 기능 및 포함된 학술정보의 양에 대한 다양한 연 구(Arendt, 2008; Callicott \& Vaughn, 2006; Chen, 2010b; Hightower \& Caldwell, 2010; Howland et al., 2009; Jascó, 2005/2009/2010; Matthew et al., 2008; Meier \& Conkling, 2008; Neuhaus et al., 2006; Nourbakhsh et al., 2012; Pomerantz, 2006 등) 가 발표되어 왔다.

구글 학술검색의 검색 기능은 분명히 기존의 유료 데이터베이스와 비교했을 때 성능면과, 다 양한 기능 제공 측면에서 떨어진다고 평가할 수 있다. 특히 시소러스, 주제어 등과 같은 통제어 휘(controlled vocabulary) 가 없는 것은 매우 구체적이고 복잡한 검색이 요구되는 분야에서 는 중대한 약점으로 작용한다. 하지만 구글 학 술검색의 가장 큰 강점은 이용이 편리하다는 점 과 기존의 도서관 데이터베이스 대부분이 서지 사항, 초록 등과 같은 문서의 일부만을 색인에 포함시키는 것과 달리 원문 전체를 검색할 수 있다는 점이다. 따라서 기존 데이터베이스에서 는 찾지 못하는 문서를 구글 학술검색에서는 검 색되는 경우가 있다.

대학도서관 사서의 관점에서 Google Scholar
를 평가할 때 가장 중요한 측면은 과연 구글 학 술검색이 기존의 전자학술 데이터베이스에 수 록된 논문 정보를 어느 정도 포함하고 있는지이 다. 구글 학술검색이 서비스를 시작한지 몇 개월 후인 2005년에 Neuhaus et al.(2006) 은 이 문 제를 조사하였다. 이들은 47 개의 전자학술데이 터베이스로부터 무작위로 50 개의 논문을 추출 하고 이들 논문의 몇 퍼센트가 구글 학술검색을 통해 검색 가능한지 조사하였다. 이 연구에 따르 면 구글 학술검색의 전자학술데이터베이스 논 문의 평균비율은 약 $60 \%$ 로 조사되었으며 개별 데이터베이스에 따라 최저 $6 \%$ 에서 최고 $100 \%$ 로 큰 편차를 보였다.

Chen(2010b)은 약5년 후인 2010년에 Neuhaus et al.(2006)의 연구에 대한 후속연구를 수행하 였다. Chen은 이전 연구에서 구글 학술검색의 편입 비율(coverage)이 $90 \%$ 인 주요 데이터베 이스 7 개와 기존 연구에 포함되지 않았지만 이 용이 많은 American Chemical Society (ACS) 발행 학술지 데이터베이스를 대상으로 역시 각 데이터베이스에서 50 개의 논문을 추출해 구글 학술검색 포함 여부를 조사하였다. 아래〈표 3$\rangle$ 은 Chen(2010b)의 주요 연구 결과를 보여준다.

Chen(2010b)의 연구에 따르면 8개의 주요 전 자학술데이터베이스 중에서 OUP(Oxford University Press) 학술지와 Project MUSE에 포

〈표 3〉 Google Scholar의 전자학술데이터베이스 논문 편입 비율: 2005년과 2010년 비교

\begin{tabular}{c|c|c|c|c|c|c|c|c}
\hline & JSTOR & ERIC & Springer & $\begin{array}{c}\text { U. of } \\
\text { Chicago }\end{array}$ & Emerald & $\begin{array}{c}\text { Oxford U. } \\
\text { Press }\end{array}$ & $\begin{array}{c}\text { Project } \\
\text { MUSE }\end{array}$ & ACS \\
\hline Neuhaus et al.(2005) & $30 \%$ & $44 \%$ & $68 \%$ & $78 \%$ & $84 \%$ & $88 \%$ & $88 \%$ & n.a. \\
\hline Chen(2010b) & $100 \%$ & $100 \%$ & $100 \%$ & $100 \%$ & $100 \%$ & $98 \%$ & $98 \%$ & $100 \%$ \\
\hline
\end{tabular}

* n.a.: Neuhaus et al. 연구에 포함되지 않음 
함된 학술지 $(98 \%, 50$ 개 논문 중에서 49 개)를 제외하고 나머지 6 개 데이터베이스의 논문을 $100 \%$ 포함하고 있는 것으로 나타났다. 따라서 2005년과 2010년의 기간 동안 구글 학술검색의 전자학술데이터베이스 편입 비율이 전반적으로 매우 향상된 것으로 평가된다. 물론 이런 결과 가 나온 주요한 이유는 구글 학술검색의 성능이 개선된 점도 있지만 해당 출판사 및 데이터베 이스 업체에서 관련 데이터를 Google에 제공해 서 보다 많은 이용자들에게 관련 논문을 노출시 키고 이용 및 인용의 증가, 논문 판매 증가를 노 린 것이 주요한 영향 요인이라고 보인다.

Chen(2010b)의 연구는 구글 학술검색이 중 복된 논문을 제거하는 de-duplication에 대해서 도 언급하고 있다. 학술데이터베이스의 경우 한 논문에 대해 단 하나의 레코드를 가지고 있는데 구글 학술검색의 경우에는 웹사이트와 학술데 이터베이스의 자료를 기초로 색인을 구축하기 때문에 여러 개의 중복된 레코드를 포함하고 있 으며 어떤 기준으로 중복된 논문을 제거하는지 가 중요한 작업이 된다. 순전히 de-duplication 기능의 관점에서 보면 구글 학술검색은 매우 우 수한 성능을 보이고 있다고 Chen은 보고하고 있다. 즉 중복된 논문을 제거하는데 구글 학술 검색이 매우 성공적이라는 것이다. 하지만 중복 된 논문 중에서 어떤 것을 선택하는지에 대해서 는 일관성이 없다고 조사되었다. 어떤 논문을 결과로 보여주어야 할 것인지 결정하는 것은 매 우 복잡한 문제이다. 이용의 관점에서 보면 동 일 논문에 대해 유료 학술데이터베이스의 레코 드를 결과에 내보내는 것보다는 논문 저자의 개
인 웹페이지나 주제 및 기관저장소(subject or institutional repositories)에 탑재된 오픈액세 스 논문을 결과로 보여주는 것이 나을 수 있다. 하지만 인용이 가능한 공식적인 기록물(version of record) 대신 출판전 논문을 보여주는 것이 바람직한가에 대한 논란이 있을 수 있다.

구글 학술검색은 이용이 매우 간편하고 방대 한 양의 학술지 논문을 검색할 수 있는 효율적 인 수단으로 부상하고 있다. 물론 기존의 도서 관 학술데이터베이스가 제공하는 다양한 검색 도구가 부족하기는 하지만 현재 출판되고 있는 학술지 논문의 상당 부분을 편입하고 있다는 점 에서 잠재적으로 도서관 학술데이터베이스의 대안으로 고려할 필요가 있다. 구글 학술검색을 도서관 데이터베이스의 대안으로 고려할 때 가 장 문제가 되는 부분은 크게 세 가지이다. 첫째, 기존 데이터베이스가 비교적 명확하고 안정된 선정기준을 가지고 있는데 반해 구글 학술검색 은 그러한 기준이 없다는 것이다. 특히 최근 돈 벌이를 목적으로 생겨나고 있는 약탈적 출판사 (predatory publishers) 가 간행하는 학술지까 지 무분별하게 검색될 수 있다는 것에 대한 우 려가 있다.6) 둘째, 이용자들이 대학도서관을 통 해서 학술지 논문을 접근하면 해당 논문을 기관 구독을 통해 대부분 무료로 접근할 수 있고 기 관구독이 포함하고 있지 않은 논문은 비교적 명 확하게 표시되어 있다. 하지만 구글 학술검색을 통해 제시된 학술지 논문의 경우에는 유료/무 료 표시가 되어 있지 않아서, 만약 이용자가 대 학의 인터넷 주소가 아닌 것으로 유료 논문을 접근하는 경우 요금지불을 요구받게 되는 상황

6) University of Colorado(Denver) 도서관 사서인 Jeffrey Beall은 약탈적 출판사 목록과 선정 이유를 아래 사이트 에서 제공하고 있다. http://metadata.posterous.com/83235355 
에 처하게 된다. 만약 어떠한 기술적인 방법을 통해 해당 도서관의 기관구독 자료를 문제없이 접근하게 되는 경우에도 이용자는 자신이 인터 넷의 무료 자료를 이용한다고 생각하고 도서관 이 해당 자료에 대해 이미 비용을 지불했다는 사실을 간과할 가능성이 높다. 마지막으로 공공 재 성격이 강한 학술정보의 접근을 구글이라는 전세계에서 가장 정보독점력이 강한 사기업에 의존하는데 대한 우려이다. 만약 구글이 지불수 단까지 제공하고 도서관과 출판사 사이에 중간 매개자의 역할을 할 수 있게 되는 것에 대한 우 려이다. 한편으로는 현재 다수의 출판사. 데이터 베이스 업체와의 거래를 단순하게 만드는 이점 이 있으나 독점화에 대한 우려가 큰 것이다.

대부분의 연구자는 앞으로도 대학도서관에서 제공하는 데이터베이스를 통해 다양한 학술정보 에 접근할 것이다. 하지만 향후 도서관의 비용 부담이 너무 높은 수준에 이르면 빅딜 모형의 지속가능성에 대한 회의와 함께 이미 이용자들 에게 익숙한 구글 학술검색을 대안으로 생각할 수 있다. 또한 오픈액세스의 활성화는 구글 학 술검색의 효율성 증대에도 분명 기여할 것이다.

\section{5. 결론 및 제언}

대학도서관 예산중에서 전자학술지 비중이 높아지고 있고, 빅딜을 통한 학술정보입수의 가 격 인상 및 소수의 출판사에 의한 과점화 등이 문제가 되면서 현재의 구독기반 학술정보, 특 히 전자학술지의 입수모형의 지속가능성에 대 한 의문이 있다. 본 연구는 빅딜로 대변되는 구 독기반 입수모형에 대한 구체적인 분석과 함께
현재 학술지 출판 및 유통 분야에서 시도되고 있는 오픈액세스와 대안적인 학술정보 검색 및 접근 도구로서의 구글 학술검색을 잠재적인 변 화세력으로 지목하여 그것들의 영향력에 대한 최근 연구를 살펴 보았다.

1990년대 중반에 시작된 빅딜 기반 학술지 구독모형은 전자학술정보 입수와 관련하여 현 재 국내외 대학에서 주도적인 모델로 자리잡았 다. 하지만 지속되는 가격인상은 향후 구독기반 모형이 유지가능한(sustainable) 모형인지에 대 한 의문을 제기하고 있으나 현실적으로는 뚜렷 한 대안이 제시되고 있지 않다. 예산상의 문제 로 빅딜 구독을 취소하는 일부 사례와 가격대응 에 강력하게 대응하는 일부 사례가 있지만 가까 운 장래에 $\mathrm{PDA}$, 즉 pay-per-view 등과 같은 방식이 구독기반 모형을 대체할 것이라고 보기 힘들다. 다만 대학도서관의 심각한 예산 문제가 더 악화된다면 이것이 새로운 변화를 가져오는 계기로 작용할 것이라고 예측된다.

2000년대부터 시작된 오픈액세스 운동은 공 공재 성격으로서의 학술정보의 생산과 자유로 운 유통을 그 목적으로 하고 있다. 오픈액세스 학술지의 출간 $(\mathrm{Gold} \mathrm{OA})$ 과 기존에 상업출판 사 등을 통해 발간된 논문을 셀프아카이빙 하 거나 주제별, 기관별 저장소(repositories)를 사 용하는 Green OA 등의 다양한 전략들이 시도 되고 있다. 오픈액세스를 통한 출판은 매년 높 은 비율로 신장되고 있으며 Web of Science와 Scopus 데이터베이스 편입비율도 증가하고 있 는 등 빠른 속도로 그 영향력이 높아지고 있다. 현재 오픈액세스 발간 학술지 논문이 전체 학술 지 논문의 약 $20 \%$ 정도 수준으로 오픈액세스가 기존의 학술출판모형을 대체했다고는 볼 수 없 
으나 조만간 중대한 분기점이 나올 수 있는 가 능성이 엿보인다. 특히 생의학(biomedicine) 분 야에서는 오픈액세스 학술지를 통한 논문 발간 이 매우 두드러지고 수학 분야 등에서는 오픈액 세스 비율이 $50 \%$ 에 육박하는 등 오픈액세스가 약진하는 분야를 주목할 필요가 있다.

2004년 11월에 서비스를 시작한 구글 학술 검색은 이용 방법이 편리하여 이미 많은 연구자 와 학생이 사용하고 있다. 구글 학술검색에 포 함된 학술지 품질에 관한 의문, 유료 학술논문 의 경우 접근 애로, 제한적인 검색 기능 등에 대 한 우려가 있지만 최근 연구는 주요 학술지의 논문 내용이 구글 학술검색을 통해 검색 및 접 근할 수 있으며 잠재적으로 대학도서관이 구독 하고 있는 데이터베이스를 일부 대체할 수 있는 수준으로 판단된다. 현재까지는 대학도서관이 제공하는 데이터베이스가 연구자들에게 보다 높 은 가치를 제공한다고 평가된다. 하지만 오픈액 세스 출판의 활성화, 대학도서관 예산의 악화, 구글 학술검색의 기능 개선 등이 지속된다면 앞 으로 구글 학술검색이 도서관의 데이터베이스 를 대체할 수 있는 가능성이 높아질 수 있다. 이 는 대학도서관과 사서의 기능에 대한 근본적인 질문을 던지게 한다는 점에서 심각하게 받아들 여질 필요가 있다.

본 논문의 논의내용은 향후 국내대학도서관 에게 많은 시사점을 제시한다. 현재 KISTI의 KESLI 컨소시엄과 KERIS를 통한 구독 기반 해외학술정보의 컨소시엄이 10 년을 넘어서 성 숙단계에 있다. 대학도서관의 사서들은 구독기 반 학술정보의 입수 업무에 익숙해졌다. 하지만 한편으로는 오픈액세스, 구글 학술검색 등과 같 은 학술지의 출판과 유통에 대한 새로운 세력의
등장은 학술커뮤니케이션 시스템 자체가 매우 유동적(volatile)이라는 점을 말해준다. 이러한 변화는 조만간 파괴적 변화로 대두할 가능성도 있다. 여기서 파괴적이라는 말은 기존의 제도와 도구를 전면적으로 대체한다는 의미이다. 구체 적으로 도서관의 정적인 예산 업무, 이용자를 위한 자료선별, 학술정보로 이용자를 인도하고 교육하는 것과 같은 구체적인 분야에서 새로운 환경이 도래할 수 있다.

예를 들어, 고정된 예산의 틀에서 자료구입 업무를 수행하는 사서의 입장에서는 전자자료 구독비의 불확실성 및 변동성은 매우 큰 위협이 다. 따라서 빅딜 계약에서 매년 일정한 폭의 인 상률에 대한 양보를 하고서라도 고정된 구독비 지출 수준을 확보하려고 한다. PDA 계약 방식 이든 다른 구독모형을 채택함으로 인해 구독료 지출에 변동성이 생기게 된다면 대학도서관 사 서는 어떻게 이에 대처할 수 있을까? 구독료 지 출의 변동성은 단순히 예산의 변동성뿐만 아니 라 서비스 제공수준에도 가변성과 불확실성을 일으킬 수 있다는 점에서 사서 업무에 상당한 복잡성을 가져올 수 있다. 도서관 예산의 가변 성은 아직은 쉽게 받아들여지기 힘든 조건이다. 최근 Canadian Research Knowledge Network (CRKN) 컨소시엄은 American Chemical Society의 전자학술지 구독 계약을 종료했는데(2012) 2001년부터 유지해오던 계약을 갱신하지 않은 주요 이유는 원문이용기반 구독료 계산 방식에 따라 구독료가 큰 폭으로 변동될 수 있다는 점 이었다. 하지만 앞으로도 고정 예산이라는 도서 관 자료 구독의 내적 환경은 지속적인 도전을 받을 것으로 예상된다는 점에서 대학도서관 사 서들은 이에 대한 구체적인 대비 시나리오가 필 
요하다고 판단된다.

이용자 교육의 분야에서도 변화가 필요하다. 최근 대학도서관에서의 이용자 교육이 도서관 이 구비하고 있는 자료(특히 전자정보원)의 사 용법을 가르쳐 주는 것에서 이용자의 정보 문제 를 해결할 수 있는 다양한 도구와 기술을 가르 치는 방향으로 가고 있는 점은 고무적이다. 특 히 일반적인 학술검색 기술을 가르치는 것에서 탈피하여 오픈액세스 자원을 포함한 다양한 주 제 분야 학술정보원을 사용하는 것과 도서관의 웹 데이터베이스와 더불어 구글 학술검색을 포 함한 무료 전자자원을 효과적으로 사용하는 것
등에 대한 교육으로 이용자 교육의 내용을 다변 화할 필요가 있다. 이렇게 하려면 사서들 자신 도 해당 주제 분야 정보원 및 그것의 활용법에 대해 지속적으로 탐구하고 훈련할 필요가 있다. 오픈액세스가 학술정보의 주도적인 출판 및 유통 방식이 되고 구글 학술검색을 통해 대다수 의 이용자가 학술정보를 검색하고 접근하는 환 경에서 대학도서관은 어떤 기관이 되어야 할지, 대학도서관 사서는 이용자와 어떤 관계를 설정 해야 하는지 깊은 고민과 함께 구체적인 대응방 안에 대한 논의가 필요하다.

\section{참 고 문 헌}

신은자 (2007). 학술지 빅딜판매의 문제점 및 개선 방안. 한국문헌정보학회지, 41(1), 373-389.

한국과학기술정보연구원 (2010). KESLI 컨소시엄 사업의 경제적 가치 분석(K-10-ID-41-01P-10). 대전: 한국과학기술정보연구원.

Arendt, J. (2008). Imperfect tools: Google Scholar vs. Traditional commercial library databases. Against the Grain, 20(2), 26-27.

Björk, B-C. (2012). The hybrid model for open access publication of scholarly articles: A failed experiment? Journal of the American Society for Information Science \& Technology, 63(8), 1496-1504. http://dx.doi.org/10.1002/asi.22709

BOAI (2002). Budapest Open Access Initiative. Retrieved from http://www.opensocietyfoundations.org/openaccess/read

Bosch, S., \& Henderson, K. (2012). Periodicals price survey 2012. Library Journal, April 30. Retrieved from http://lj.libraryjournal.com/2012/04/funding/coping-with-the-terrible-twins-periodicals-p rice-survey-2012/

Callicott, B., \& Vaughn, D. (2006). Google Scholar vs. Library Scholar: Testing the performance of Schoogle. Internet Reference Services Quarterly, 10(3-4), 71-88. 
Canadian Research Knowledge Network (November 26, 2012). CRKN to terminate national agreement with the ACS. Retrieved from http://www.crkn.ca/communications/crkn-to-terminate-national-agreement-with-the-acs

Carr, P., \& Collins, M. (2009).Acquired articles through unmediated, user-initiated, pay-per-view transactions: An assessment of current practices. Serials Review, 35(4), 272-277.

Carr, P. L. (2009-2010). Forcing the moment to its crisis: Thoughts on pay-per-view and the perpetual access ideal. Against the Grain, 21(6), 16-18.

Chamberlain, C., \&MacAlpine, B. (2008). Pay-per-view article access: A viable replacement for subscriptions? Serials, 21(1), 30-34.

Chen, X. (2010a). The declining value of subscription-based abstracting and indexing services in the new knowledge dissemination era. Serials Review, 36(2), 79-85. http://dx.doi.org/10.1016/j.serrev.2010.02.010

Chen, X. (2010b). Google Scholar's dramatic coverage improvement five years after debut. Serials Review, 36(4), 221-226. http://dx.doi.org/10.1016/j.serrev.2010.08.002

Christensen, C. M. (1997). The innovator's dilemma: When new technologiescause great firms to fail. Boston, MA: Harvard Business School Press.

Danneels, E. (2004). Disruptive technology reconsidered: A critique and research agenda. Journal of Product Innovation Management, 21, 246-258.

EBSCO (2012). 2012 EBSCO library collections and budgeting trends survey. Retrieved from http://www2.ebsco.com/EN-US/NEWSCENTER/Pages/ViewArticle.aspx?QSID = 360

Gargouri, Y., Larivière, V., Gingras, Y., Carr, L., \& Harnad, S. (2012). Green and gold open access percentages and growth, by discipline. Retrieved from http://arxiv.org/abs/1206.3664

Hightower, C., \& Caldwell, C. (2010).Shifting sands: Science researchers on Google Scholar, Web of Science, and PubMed, with implications for library collections budgets. Issues in Science and Technology Librarianship, 63. Retrieved from http://www.istl.org/10-fall/refereed3.html

Howland, J. L., Wright, T. C., Boughan, R. A., \& Roberts, B. C. (2009). How scholarly is Google Scholar? A comparison to library databases. College \& Research Libraries, 70(3), 227-234.

Jacsó, P. (2005). Google Scholar: The pros and the cons. Online Information Review, 29(2), 208-214. http://dx.doi.org/10.1108/14684520510598066

Jacsó, P. (2009). Google Scholar's ghost authors. Library Journal, 134(18), 26-27.

Jacsó, P. (2010). Metadata mega mess in Google Scholar. Online Information Review, 34(1), 175-191. http://dx.doi.org/10.1108/14684521011024191 
Laakso, M., Welling, P., Bukvova, H., Nyman, L., Björk, B-C., \& Hedlund, T. (2011). The development of open access journal publishing from 1993 to 2009. PLOS ONE, 6(6), e20961. http://dx.doi.org/10.1371/journal.pone.0020961

Laakso, M., \& Björk, B-C. (2012). Anatomy of open access publishing: A study of longitudinal development and internal structure. BMC Medicine, 10, 124. http://dx.doi.org/10.1186/1741-7015-10-124

Matthew, E. F., Eleni, I. P., George, A. M., \& Georgios P. (2008). Comparison of PubMed, Scopus, Web of Science, and Google Scholar: Strengths and weaknesses. The Journal of the Federation of American Societies for Experimental Biology, 22(2), 338-342. http://dx.doi.org/10.1096/fj.07-9492LSF

Meier, J., \& Conkling, T. (2008). Google Scholar's coverage of the engineering literature: An empirical study. Journal of Academic Librarianship, 34(3), 196-201.

Morrison, H. (2012). About 30\% of peer-reviewed scholarly journals are now open access. Retrieved from http://poeticeconomics.blogspot.kr/2012/05/about-30-of-peer-reviewed-scholarly.html

Neuhaus, C., Neuhaus E., Asher, A., \& Wrede, C. (2006). The depth and breadth of Google Scholar: An empirical study. portal: Libraries and the Academy, 6(2), 127-141. http://dx.doi.org/10.1353/pla.2006.0026

Nourbakhsh, E., Nugent, R., Wang, H., Cevik, C., \& Nugent, K. (2012). Medical literature searches: A comparison of PubMed and Google Scholar. Health Information and Libraries Journal, 29(3), 214-222. http://dx.doi.org/10.1111/j.1471-1842.2012.00992.x

Pomerantz, J. (2006). Google Scholar and 100\% availability of information. Information Technology and Libraries, 25(2), 52-56.

Poynder, R. (2011a). Interview with DerkHaank, CEO, Springer Science+Business Media: Not looking for sympathy. Information Today, 28(1). Retrieved from http://www.infotoday.com/IT/jan11/Interview-with-Derk-Haank.shtml

Poynder, R. (2011b). The big deal: Not price but cost. Information Today, 28(8). Retrieved from http://www.infotoday.com/it/sep11/The-Big-Deal-Not-Price-But-Cost.shtml

Rapp, D. (2011). RLUK announces new publisher terms; ARL and LYRASIS sign negotiation agreement. Library Journal, December 5. Retrieved from http://www.thedigitalshift.com/2011/12/digital-libraries/rluk-announces-new-publisher-t erms-arl-and-lyrasis-sign-negotiation-agreement/

Suber, P. (2004. June 21). Open access overview: Focusing on open access to peer-reviewed research articles and their preprints. Retrieved from 
http://www.earlham.edu/ peters/fos/overview.htm

Suber, P. (2012). Open access. Cambridge, MA: MIT Press.

UW Today. (2010. January 7). Libraries reduce journal subscriptions and book orders; Budget cuts affect online as well as print materials. Retrieved from http://www.washington.edu/news/ Weicher, M., \& Zhang, T. X. (2011). Unbundling the Big Deal with patron driven acquisition of eJournals. Proceedings of the 77th IFLA General Conference and Assembly. Meeting 164-Access and Innovation: Delivering Information to All-Serials and Other Continuing Resources Section. Retrieved from http://conference.ifla.org/past/ifla77/164-weicher-en.pdf

\section{- 국문 참고문헌에 대한 영문 표기}

(English translation of references written in Korean)

Korea Institute of Science and Technology Information (2010). Economic analysis of KESLI consortium(K-10-ID-41-01P-10). Daejeon: Korea Institute of Science and Technology Information.

Shin, Eun-Ja (2007). Analysis and proposals concerning big deals of scholarly journals. Journal of the Korean Society for Library and Information Science, 41(1), 373-389. 